\title{
Effect of treatment with botulinum toxin on spasticity
}

\author{
T.K. Das and D.M. Park \\ Southend District Stroke Unit, Rochford Hospital, Essex SS4 IRA, UK.
}

\begin{abstract}
Summary: Botulinum toxin, a product of Clostridium botulinum, produces presynaptic neuromuscular block by preventing release of acetylcholine from nerve endings. The toxin was injected directly into the skeletal muscles of six patients with severe spasticity due to stroke-related hemiplegia. It produced both subjective and objective improvement. The toxin injections were well tolerated and no significant side effect was reported.
\end{abstract}

\section{Introduction}

Botulinum toxin $\mathrm{A}$ is one of seven neurotoxins produced by Clostridium botulinum and causes the clinical syndrome of botulism, a progressive flaccid paralysis of muscles following the ingestion of the toxin. ${ }^{1}$ Local injection of very small doses of the toxin produces local paralysis, and individual muscles can therefore be selectively weakened. ${ }^{2}$ It produces presynaptic neuromuscular block by preventing release of acetylcholine from nerve endings. The toxin interferes with the uptake of cytoplasmic acetylcholine by the presynaptic vesicles in the motor endplate. ${ }^{3}$ Therapeutically, the toxin has been used for the treatment of blepharospasm, hemifacial spasm, spasmodic torticollis, writers' cramp and other focal dystonias. ${ }^{3-5}$ The duration and extent of the paralysis depend on the dose injected. No systemic side effect has yet been reported. The average duration of symptomatic relief is $8-12$ weeks. ${ }^{3.4}$

Spasticity following stroke interferes with the quality of movement and may prevent even basic normal postural reactions. It causes dysfunction which may be more disabling than the loss of muscle power or limitation of range of movement. Occasionally, contractures may develop in spite of intensive physiotherapy. In this situation the spastic limb is also frequently uncomfortable and poses a real problem in rehabilitation.

\section{Patients and methods}

Six patients with post-stroke hemiplegia were initially selected for treatment. Each had a degree of contractures resistant to available therapy. Their ages ranged

Correspondence: T.K. Das, M.D., M.R.C.P., Department of Neurology, Southend Hospital, Southend-on-Sea SSO 0RY, UK.

Accepted: 28 November 1988 from 30 to 70 years and the duration of their spasticity was between 2 years and 6 months. The upper limb spasticity was evaluated by using the Oswestry scale of grading: ${ }^{6} 0$ - solely spasticity, no willed movement possible; 1 - very severe spasticity, movement very poor; 2 - severe spasticity, movement poor; 3 moderate spasticity, movement fair; 4 - mild spasticity, movement good; 5 - no spasticity, movement normal.

The range of movements were measured with a goniometer. The biceps, flexor digitorum profundus and flexor carpi ulnaris muscles were chosen for treatment. The range of active and passive movements of the respective joints was noted and the muscles were surveyed for spasticity. The motor points were identified by standard neurophysiological techniques. Botulinum A toxin, $20 \mathrm{ng}$ diluted in $4 \mathrm{ml}$ of normal saline, was infiltrated along the plane of motor points in each of two selected muscles (e.g. biceps and forearm common flexors). Patients were examined daily for the first week and then at weekly intervals for 4 months. The body temperature, blood pressure and the heart and respiratory rates were recorded on three consecutive days following the toxin injections.

The patients were asked to assess subjective improvement especially pain relief and discomfort and also to comment on any other effects. Functional abilities of all patients were recorded every two weeks using the Barthel index. ${ }^{7.8}$

\section{Results}

All six patients remained well. There was no local discomfort or systemic side effects. Morale of the patients was good although their own assessments of subjective improvement indicated only slight relief of discomfort in the treated arms.

The spasticity was substantially relieved (Table I)

C) The Fellowship of Postgraduate Medicine, 1989 
following the toxin treatment. There was an improvement in all the scores in all the subjects. The range of movements (both at elbow and wrist joint) also improved considerably (Table II); the effect on flexor digitorum profundus was most noticeable. Repeated measurements of Barthel scores showed some improvement of overall functional status (Table III) and increased independence in self care and mobility skills in all the patients.
Table I Spasticity score - before and after toxin injections (Oswestry Scale)

\begin{tabular}{lcccccc}
\hline & Before & \multicolumn{5}{c}{ After injection (weeks) } \\
Patient & injection & 1 & 2 & 4 & 8 & 12 \\
\hline 1 & 0 & 3 & 4 & 4 & 4 & 4 \\
2 & 1 & 4 & 5 & 4 & 4 & 4 \\
3 & 2 & 5 & 5 & 5 & 5 & 5 \\
4 & 1 & 3 & 4 & 4 & 4 & 4 \\
5 & 0 & 2 & 4 & 4 & 4 & 4 \\
6 & 0 & 0 & 2 & 4 & 4 & 3 \\
\hline
\end{tabular}

Table II Additional range of movement (in degrees) following toxin injections

\begin{tabular}{|c|c|c|c|c|c|c|c|c|}
\hline \multirow[b]{3}{*}{ Patient } & \multicolumn{4}{|c|}{1 month after injection } & \multicolumn{4}{|c|}{3 months after injection } \\
\hline & \multicolumn{2}{|c|}{ Wrist joint } & \multicolumn{2}{|c|}{ Elbow joint } & \multicolumn{2}{|c|}{ Wrist joint } & \multicolumn{2}{|c|}{ Elbow joint } \\
\hline & Active & Passive & Active & Passive & Active & Passive & Active & Passive \\
\hline 1 & 30 & 75 & 30 & 120 & 25 & 75 & 20 & 90 \\
\hline 2 & 50 & 90 & 90 & 150 & 50 & 85 & 80 & 140 \\
\hline 3 & 75 & 120 & 110 & 160 & 70 & 120 & 100 & 150 \\
\hline 4 & 20 & 70 & 30 & 90 & 20 & 70 & 25 & 90 \\
\hline 5 & 30 & 85 & 25 & 80 & 25 & 85 & 30 & 85 \\
\hline 6 & 25 & 70 & 20 & 70 & 20 & 70 & 15 & 70 \\
\hline
\end{tabular}

Table III Comparison of Barthel index (maximum score of 100) before and after toxin injections

\begin{tabular}{lcccc}
\hline Patient & $\begin{array}{c}\text { Initial } \\
\text { score }\end{array}$ & I month & 2 months & 3 months \\
\hline 1 & 65 & 80 & 80 & 75 \\
2 & 75 & 85 & 85 & 85 \\
3 & 60 & 75 & 70 & 70 \\
4 & 70 & 75 & 75 & 75 \\
5 & 65 & 70 & 75 & 70 \\
6 & 55 & 65 & 60 & 60 \\
\hline
\end{tabular}

\section{Discussion}

Muscle weakness and spasticity are the most apparent physical consequences of cerebro-vascular accidents. ${ }^{9}$ Spastic limbs refractory to conventional therapy may be very disabling for the patients and pose a real challenge towards ultimate rehabilitation.

The patients in this study were refractory to available therapy and appeared to have responded well to local injections of botulinum toxin. The toxin acts presynaptically at nerve terminals to prevent calcium-dependent release of acetylcholine. ${ }^{10}$ When injected locally the effect is of a chemical denerv-

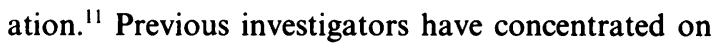
using local injections of botulinum toxin for the treatment of blepharospasm, torticollis, laryngeal dystonia, oromandibular dystonia and other disabling focal dystonias. Our observations are, of course, uncontrolled and the results may well include a non-specific element attributable to interest in a neglected area of clinical research.

We emphasize the value of using botulinum toxin in the treatment of post-stroke spasticity. Our observations indicate that local injection of the toxin may be extremely beneficial in relieving spasticity and helps to improve the functional abilities of the patient. The method of treatment is simple, safe and effective. It is too soon to comment on how often injections may need to be repeated or how acceptable this would be to the patients. Further follow up will also demonstrate whether repeated injections are required for sustained benefit.

\section{Acknowledgements}

We are grateful to Dr Goran Jamal for assistance with the neurophysiological studies. We would also like to thank the staff of Southend Hospital Pharmacy and The Vaccine Research and Production Laboratory for the supply of Botulinum toxin A. 


\section{References}

1. Larson, H.E. Botulism, gas gangrene and clostridium gastrointestinal infections. In: Weatherall, D.J., Ledingham, J.G.G. \& Warrell, D.A. (eds) Oxford Textbook of Medicine. Oxford University Press, Oxford, 1987; 5.270-5.277.

2. Scott, A.B. Botulinum toxin injection into extra-ocular muscles as an alternative to strabismus surgery. Ophthalmology 1980, 87: 1044-1049.

3. Elston, J.S. Long-term results of treatment of idiopathic blepharospasm with botulinum injections. $\mathrm{Br} \mathrm{JOphthal-}$ mol 1987, 71: 664-668.

4. Elston, J.S. \& Ross-Russell, R.W. Effect of treatment with botulinum toxin on neurogenic blepharospasm. $\mathrm{Br}$ Med J 1985, 290: 1857-1859.

5. Tsui, J.KC., Eisen, A., Stoessl, A.J., Calne, S. \& Calne, D.B. Double-blind study of botulinum toxin in spasmodic torticollis. Lancet 1986, ii: 245-247.

6. Goff, B. Grading of spasticity and its effect on voluntary movement. Physiotherapy 1976, 62: 358-361.
7. Mahoney, F.I. \& Barthel, D.W. Functional evaluation: Barthel Index. Md State Med J 1965, 14: 61-65.

8. Grangers, C.V., Dewis, L.S., Peters, N.C. et al. Stroke rehabilitation: analysis of repeated Barthel index measures. Arch Phys Med Rehabil 1979, 60: 14-17.

9. Landau, W.M. Spasticity: The fable of a neurological demon and the emperor's new therapy. Arch Neurol 1974, 31: $217-219$.

10. Kao, I., Drachman, D.B. \& Price, D.L. Botulinum toxin: mechanism of presynaptic blockade. Science 1976, 193: $1256-1258$.

11. Brin, M.F., Fahn, S., Moskowitz, C. et al. Localized injections of botulinum toxin for the treatment of focal dystonia and hemifacial spasm. In: Fahn, S. (ed.) Advances in Neurology. Raven Press, New York, 1988, 50: Dystonia 2: 599-608. 